\title{
Increased concentration of metronidazole and its hydroxy metabolite in colon cancer in women
}

\author{
Anna Sadowska1, Bogusław Kędra², Dariusz Cepowicz², Lech \\ Rodziewicz ${ }^{3}$, Anna Fiedorowicz ${ }^{1}$, Sławomir Prokopiuk ${ }^{1}$, Wojciech Miltyk ${ }^{4}$, \\ Halina Car $^{1}$ \\ 1Department of Experimental Pharmacology, Medical University of Bialystok, Szpitalna 37, PL 15-295 Białystok, Poland \\ ${ }^{2}$ 2nd Department of General and Gastroenterological Surgery, Medical University of Bialystok, M. Skłodowskiej- \\ Curie 24A, PL 15-276 Białystok, Poland \\ ${ }^{3}$ Department of Hygiene Veterinary, Zwycięstwa 26a, PL 15-959 Białystok, Poland \\ ${ }^{4}$ Laboratory of Pharmaceutical Analysis, Medical University of Bialystok, Mickiewicza 2D, PL 15-089 Białystok, Poland \\ Correspondence: Halina Car, e-mail: hcar@umb.edu.pl
}

\begin{abstract}
:
Background: Metronidazole (MTZ) is indicated in the prevention of infections during surgical procedures. However, some data have shown that metronidazole has carcinogenic potential.

Methods: In the present work, we determined concentrations of metronidazole and its hydroxy metabolite (MTZOH) in colorectal cancer patients. MTZ and MTZOH were measured in tumor tissue and surrounding healthy tissue by LC-ESI-MS-MS method.

Results: We found different concentration of MTZ and MTZOH in colorectal cancer and healthy tissue. Interestingly, we noted a higher level of the above substances in women $v s$. men, both in healthy and cancerous gut.

Conclusion: We suggest that women are more exposed to a potential carcinogenic effect of metronidazole than men.
\end{abstract}

\section{Key words:}

metronidazole, MTZOH, colorectal cancer, human, women

\section{Introduction}

Colorectal cancer is the most common cancer diagnosed in Europe and also one of the leading causes of cancer deaths - over 212,000 deaths in Europe in $2008[5,9,11]$. In most people, colorectal cancer develops slowly over several years. Before it develops, a growth of tissue or tumor usually begins as a noncancerous polyp on the colon or rectum (cancer.org). Another type of pre-cancerous stage is called dyspla- sia which over time can change into cancer. Dysplasia occurs in people who have had ulcerative colitis or Crohn's disease for a long time [5]. These conditions require treatment and the medications used have not always been tested for carcinogenicity. The only effective treatment for this disease is surgery [3]. However, the tumor resection is associated with high risk of perioperative infections.

Currently, the most important in the prevention of infections is perioperative antibiotic prophylaxis 
which is significantly limiting the frequency of infections of surgical wounds [6]. There are many combinations of antibiotics and chemotherapeutic agents used in surgical prophylaxis. In surgical patients, antimicrobial prophylaxis is indicated particularly in the surgery of large intestine and rectum where anaerobic bacteria predominate, particularly Bacteroides fragilis. Therefore, the most commonly used regimens are cephalosporins and/or aminoglycosides and metronidazole. These are the medications which are widely used in various diseases caused by microorganisms. In addition to antimicrobial activity and on the basis of their toxic potential, one can hypothesize that these drugs may also affect healthy tissues as well as modify the tumor mass. Thus, the above substances need further examination. It was shown that metronidazole (MTZ), a chemotherapeutic agent, is genotoxic and can lead to cancer formation in rodents $[4,7]$. Metronidazole is an important drug for various infections induced by anaerobic bacteria. Excellent penetration into tissues, including central nervous system, bones and joints, combined with bactericidal activity make metronidazole very useful in the treatment of patients with brain abscesses, skin infections and soft tissue, bone and joint infections, or endocarditis. Although patients before tumor resection receive metronidazole or metronidazole along with other antibiotics as a normal rule, the influence of MTZ on both healthy and cancerous tissues has not been described yet. It is also not known whether the MTZ penetration in healthy tissue differs from this of cancerously modified one and whether drug absorption and its metabolism undergo any changes. Identification of the differences in drug kinetics creates a new potential for grading of tumor tissue pathophysiology. These data could also indicate that the reconsideration of MTZ usage in patients suffering from colorectal cancer is a must.

Therefore, the aim of our study was to determine the concentration of MTZ and its active hydroxy metabolite (MTZOH) in healthy colon tissue and tumor revised.

\section{Materials and Methods}

\section{Patients}

The study was performed on colorectal resection specimens removed from cancer and from healthy tissue. The tissues were obtained from both women aged $74 \pm 8$ years $(n=11)$ and men aged $63 \pm 18$ years $(n=8)$. Individuals were divided into 2 groups: patients with metastases $(\mathrm{N}+)$ and without metastases (N0) to lymph nodes. Colorectal cancer diagnosis was based on clinical symptoms, colonoscopy and histopathological analysis of tumor and surrounding lymph nodes taken during surgery. The patients revealed $\mathrm{T} 3 \mathrm{~N} 0$ or $\mathrm{T} 3 \mathrm{~N}+$ stage of tumor extent. $\mathrm{T}$ describes the extent of spread through the colorectal layers (the depth of the primary tumor), $\mathrm{N}$ estimates metastasis to regional lymph nodes. The scale used for grading colorectal cancers ranges from G1 to G4, dependently on the differentiation status of the cancer tissue. All patients were classified as G2 histological grade of tissue differentiation.

\section{Drug}

All patients had been given $500 \mathrm{mg}$ of the metronidazole iv $4 \mathrm{~h}$ prior to surgery.

\section{Tissue samples}

Samples of cancer and surrounding healthy colon tissue were obtained about 4-5 h after administration of MTZ. Tumor size (diameter) was approximately the same in all patients $(4.63 \pm 1.5 \mathrm{~cm})$.

\section{LC-ESI-MS-MS method of MTZ and MTZOH evaluation}

\section{Chemicals and reagents}

Metronidazole (MTZ) as well as its hydroxy metabolite (MTZOH) and deuterated internal standard (IS) hydroxymethylnitroimidazole d3 (HMMNI d3) were obtained from Riedel-de-Haën (Fluka, Buchs, Switzerland). Acetonitrile, methanol LC-MS, methanol LC, acetonitrile LC, acetone, formic acid (80-100\%) all analytical grades were purchased from Merck (Darmstadt, Germany). Acetic acid (95.5\%), sodium sulfate, ammonia solution (25\%) were obtained from Baker (Deventer, The Netherlands). Strata SCX $(500 \mathrm{mg} / 3 \mathrm{ml})$ solid phase extraction (SPE) cartridges were supplied by Phenomenex (Cat. No. 8B-SO10HBJ).

Standard solutions were prepared according to the method described by Rodziewicz and Zawadzka [14]. 


\section{Sample preparation}

The sample was weighed into glass tube and internal standard $(100 \mathrm{ng} / \mathrm{ml}$ of internal standard of HMMNI$\mathrm{d} 3,100 \mu \mathrm{l})$ as well as acetonitrile $(50 \mathrm{ml})$ were added and vortex-mixed vigorously for $1 \mathrm{~min}$. After adding $5 \mathrm{~g}$ of sodium sulfate, the sample was mixed and then centrifuged at $3500 \times \mathrm{g}$ at temperature below $6^{\circ} \mathrm{C}$ for $10 \mathrm{~min}$. The supernatant was transferred into a $50 \mathrm{ml}$ flask through $15 \mathrm{~g}$ of sodium sulfate and $5 \mathrm{ml}$ of acetic acid was added. The extract was cleaned up on SCX column. The column was conditioned with $5 \mathrm{ml}$ of $5 \%$ acetic acid in acetonitrile, washed with $5 \mathrm{ml}$ of acetone, $5 \mathrm{ml}$ of methanol and $5 \mathrm{ml}$ of acetonitrile, and, finally, dried for $10 \mathrm{~min}$. The nitroimidazoles were then eluted with $5 \mathrm{ml}$ of 5\% ammonia in acetonitrile. The sample was evaporated to dryness under a stream of nitrogen at $32^{\circ} \mathrm{C}$.

\section{Calibration curves}

Calibration curves were constructed using analyte/internal standard peak area ratio vs. concentration of analyte. The peak-area ratios of analyte to internal standard were calculated using Analyst 1.4 Software.

\section{LC-ESI-MS-MS}

LC analyses were performed on a Luna C18(2) column $(150 \times 2 \mathrm{~mm}$ i.d., $3 \mu \mathrm{m})$ (Phenomenex, Torrance, USA) using an Agilent 1100 series liquid chromatograph equipped with a binary pump and an autosampler (Agilent Technologies, Waldbronn, Germany). MS analyses were carried out on an API 4000 triple stage quadruple mass spectrometer (Applied Biosystems, Foster City, CA, USA) equipped with a turbo ion spray interface. The instrument was operated in Multiple Reaction Monitoring (MRM) mode using the following transitions: $\mathrm{m} / \mathrm{z} \quad 188 \rightarrow 123,188 \rightarrow 126$ for $\mathrm{MTZOH}$ and $\mathrm{m} / \mathrm{z} 161 \rightarrow 143$ for HMNNI d3 (IS) d5, with collision energies (CE) of 20, 15 and $19 \mathrm{eV}$, respectively.

\section{Statistical analysis}

The data are presented as the means \pm SD. The statistical significance of the differences between the means was determined by Student's $t$-test; $\mathrm{p}<0.05$ was considered as the level of significance.

\section{Results and Discussion}

The concentration of MTZ and MTZOH evaluated in tumors equaled $3.86 \pm 2.05 \mu \mathrm{g} / \mathrm{g}$ tissue and 0.54 $\pm 0.66 \mu \mathrm{g} / \mathrm{g}$ tissue whereas in healthy tissue it was $2.97 \pm 1.46 \mu \mathrm{g} / \mathrm{g}$ tissue and $0.49 \pm 0.49 \mu \mathrm{g} / \mathrm{g}$ tissue, respectively. The amount of $\mathrm{MTZ}$ and $\mathrm{MTZOH}$ in $\mathrm{N}+$ cancer $(2.16 \pm 1.26$ and $0.36 \pm 0.44 \mu \mathrm{g} / \mathrm{g}$ tissue $)$ was slightly decreased in comparison with healthy tissue $(2.98 \pm 1.59$ and $0.41 \pm 0.57 \mu \mathrm{g} / \mathrm{g}$ tissue). Oppositely, both MTZ and MTZOH levels in N0 patients (4.39 \pm 3.88 and $0.85 \pm 0.97 \mu \mathrm{g} / \mathrm{g}$ tissue) were elevated in tumors $v s$. healthy colon $(2.96 \pm 1.54$ and $0.63 \pm 0.39 \mu \mathrm{g} / \mathrm{g}$ tissue). A comparison of metastatic and non-metastatic carcinoma showed much higher concentrations of MTZ and MTZOH (2-fold) in N0 vs. N+ tumor tissue. Interestingly, cancers removed from women presented considerably higher MTZ concentration than those from men (Tab. 1). Similar results were obtained in healthy tissue where MTZ level reached significantly higher values for women in relation to men. However, it should be noted that both men and women tumor tissues revealed increased concentration compared with the healthy ones, but these differences were not statistically significant. The content of MTZOH was higher in both healthy and tumor tissues in female group when compared to male patients, however, not reaching statistical significance.

We noticed the tendency to enhanced MTZ accumulation in both metastatic $(3.81 \pm 1.24 \mu \mathrm{g} / \mathrm{g}$ tissue $)$ and non-metastatic $(6.04 \pm 2.17 \mu \mathrm{g} / \mathrm{g}$ tissue $)$ female tumor tissues in comparison to men: $1.98 \pm 1.18 \mu \mathrm{g} / \mathrm{g}$ tissue $(\mathrm{N}+)$ and $3.08 \pm 1.22 \mu \mathrm{g} / \mathrm{g}$ tissue $(\mathrm{N} 0)$ which did not gain statistical significance.

In the study, we found a differential (not statistically significant) concentration of MTZ in colorectal cancer and surrounding healthy tissue, probably due to greater absorption and accumulation of the chemotherapeutic in carcinoma vs. non-affected tissue. Absorption as well as accumulation of metronidazole may depend on the tumor size and its morphological structure. However, we noted approximately the same tumor size in all patients. Larger necrotic tumors due to increased hypoxia may absorb greater amounts of the drug, which may explain increased (tendency) concentration of MTZ in tumor.

Nevertheless, tumors presented distinct MTZ levels, dependently on the metastatic status. Metastatic tumor $(\mathrm{N}+)$ revealed decreased (not significant) concen- 
Tab. 1. Concentration of $M T Z$ and $M T Z O H ~(\mu \mathrm{g} / \mathrm{g}$ tissue) in tumor and healthy tissue of colorectal cancer patients

\begin{tabular}{lcccc}
\hline & \multicolumn{3}{c}{ Men } & \multicolumn{2}{c}{ Women } \\
\cline { 2 - 5 } & MTZ & MTZOH & MTZ & MTZOH \\
\hline Tumor & $2.534 \pm 1.26$ & $0.123 \pm 0.05$ & $4.826 \pm 2.00^{*}$ & $0.794 \pm 0.749$ \\
Healthy & $1.62 \pm 0.473$ & $0.213 \pm 0.07$ & $3.786 \pm 1.195^{*}$ & $0.658 \pm 0.58$ \\
\hline
\end{tabular}

${ }^{*} p<0.05$ men (MTZ) vs. women (MTZ)

tration of the drug in comparison to non-metastatic tissue (N0). Reduced drug absorption and decreased accumulation in tumors of metastatic patients could suggest that MTZ, apart from the primary tumor, penetrates into lymph node metastatic tissues. Thus, we hypothesize that pharmacokinetics is amended in metastatic and non-metastatic cancer. In addition, we noted higher content of measured MTZ in women $v s$. men, both in healthy and cancerous gut. There still remains the question what determines the differences in MTZ concentration between men and women, especially when considering patients' age, with hormone effects excluded.

These findings are important from a clinical point of view as IARC classified MTZ as an animal carcinogen $[13,17]$. The potential of MTZ to induce cancer has been under discussion since Rustia and Shubik reported the induction of tumors in mice and rats by this drug [15]. They observed a significant increase of lung tumors and malignant lymphomas in female Swiss mice. Female rats developed hepatomas and mammary tumors while in males the number of pituitary and testicular tumors was elevated $[2,16]$. Another study on animal carcinogenicity was performed by Chacko and Bhide [7]. After MTZ intragastrical administration to male and female Swiss mice, they observed cystic ovaries, tumors of lung, spleen, liver and thymus in a total of 13 females out of 40 . In treated males, 8 out of 38 developed tumors which included liver hemangiomas, lung and liver tumors [7]. On the basis of the experiments mentioned above, one can easily assume that female animals developed tumor more often than male ones.

The data concerning MTZ human carcinogenicity are still inconclusive. There have been few epidemiological studies trying to evaluate the relationship between human cancer and the exposure to MTZ specifically. The incidence of cervical cancer in women treated with
MTZ for vaginal trichomoniasis was found in epidemiological studies. However, trichomoniasis is a risk factor for cervical cancer [1, 10]. Falagas et al. [8] determined the influence of cancer after exposure to MTZ in comparison to patients that had not been exposed to the drug. The main conclusion of their work was that the incidence (rate) of cancer among people who had been given MTZ was almost the same as in the control group [8]. However, there is a lack of a large cohort of people treated with MTZ to clearly establish the risk that MTZ treatment carries with itself.

The pharmacokinetics of MTZ in humans is not completely established, but it is known that the drug is metabolized mainly in the liver by cytochrome P450 system into hydroxy metabolites, acetic acid metabolites and glucuronide derivative. Hydroxy metabolite (MTZOH) and the parent drug are biologically active, where MTZOH has $30-60 \%$ of MTZ biological activity. MTZOH has a longer half-life $(12 \mathrm{~h})$ and contains nearly $50 \%$ of the antitrichomonal activity of metronidazole $[4,12]$. With reference to the above data, we decided to examine the major metabolite of metronidazole. Our preliminary studies showed that the level of MTZOH, dependently on sex and metastases, displayed similar direction of changes as MTZ, which suggests similar metabolism in tumor and non-affected tissue.

Patients after resection of colon cancer receive MTZ to avoid complications caused by infections. Metronidazole and its metabolite MTZOH can be accumulated in tissues with low redox status and probably in metastatic cells. On the basis of the MTZ carcinogenic potential and the unknown MTZOH activity in tumor, it can be assumed that metronidazole may enhance the invasiveness of cancer. The results of our study may suggest that women are more exposed to such an effect of metronidazole than men. 


\section{Acknowledgment:}

This work was supported by the grant No. 3-10591L from the State Committee for Scientific Research, Warszawa, Poland

\section{References:}

1. Beard CM, Noller KL, O'Fallon WM, Kurland LT, Dockerty MB: Lack of evidence for cancer due to use of metronidazole. N Eng J Med, 1979, 301, 519-522.

2. Bendesky A, Menandez D, Ostrosky-Wegman P: Is metronidazole carcinogenic? Mutat Res, 2002, 511, 133-144.

3. Berger AC, Sigurdson ER, LeVoyer T, Hanlon A, Mayer RJ, Macdonald JS, Catalano PJ, Haller DG: Colon cancer survival is associated with decreasing ratio of metastatic to examined lymph nodes. J Clin Oncol, 2005, 23, 8706-8712.

4. Brunton LL, Lazo JS, Parker KL: Chemotherapy of parasitic infections. In: Goodman \& Gilman's The Pharmacological Basis of Therapeutics vol. 2, 1st Polish edn., Eds. Buczko W, Krzemiński TF, Czuczwar SJ, Czelej, Lublin, 2007, 1127-1130.

5. Byrne L: Colorectal cancer. MPHP 439 - Online Textbook Chapter December 3, 2008.

6. Chaber A: Antibiotic prophylaxis in alimentary tract surgery (Polish). Współczesna Onkologia, 1999, 2, 86-89.

7. Chacko M, Bhide SV: Carcinogenicity, perinatal carcinogenicity and teratogenicity of low dose metronidazole (MTZ) in Swiss mice. J Cancer Res Clin Oncol, 1986, 112, 135- 140 .

8. Falagas ME, Walker AM, Jick H, Ruthazer R, Griffith J, Snydman DR: Late incidence of cancer after metronida- zole use: A matched metronidazole user/nonuser study. Clin Infect Dis, 1998, 26, 384-388.

9. Ferlay J, Parkin DM, Steliarova-Foucher E: Estimates of cancer incidence and mortality in Europe in 2008. Eur J Cancer, 2010,46, 765-781.

10. Friedman GD, Ury HK: Initial screening for carcinogenicity of commonly used drugs. J Natl Cancer Inst, 1980, $65,723-733$.

11. Jemal A, Siegel R, Xu J, Ward E: Cancer statistics, 2010. CA Cancer J Clin, 2010, 60, 277-300.

12. Lamp KC, Freeman CD, Klutman NE, Lacy MK: Pharmacokinetics and pharmacodynamics of the nitroimidazole antimicrobials. Clin Pharmacokinet, 1999, 36, 353-373.

13. Report on Carcinogens, Twelth Edition (2011) http://ntp.niehs.nih.gov/go/roc12.

14. Rodziewicz L, Zawadzka I: Determination of nitrofuran metabolites residues in animal tissues by LC-MS/MS method (Polish). Rocz PZH, 2007, 58, 625-632.

15. Rustia M, Shubik P: Experimental induction of hepatomas, mammary tumors and other tumors with metronidazole in noninbred Sas:MRC/W1/BR rats. J Natl Cancer Inst, 1979, 63, 863-867.

16. Rustia M, Shubik P: Induction of lung tumors and malignant lymphomas in mice by metronidazole. J Natl Cancer Inst, 1972, 48, 721-729.

17. World Health Organization, WHO Pharm Newslett, 1998, 3/4, 15.

Received: November 24, 2011; in the revised form: April 18, 2012; accepted: May 10, 2012 